\title{
Physicians' Life Satisfaction in Bhutan: A Nationwide Survey
}

\author{
Ugyen Dem, Marnina Swartz, Ilona Mirecki, Yoram Barak* \\ Abarbanel Mental Health Center, Affiliated with the Sackler School of Medicine, Tel-Aviv University, Tel Aviv, \\ Israel \\ Email:u_dema@yahoo.com,marnina.swartz@abr.health.gov.il, Ilona.mirecki@gmail.com, \\ mdybarak@gmail.com
}

Received 24 December 2015; accepted 23 January 2016; published 26 January 2016

Copyright (C) 2016 by authors and Scientific Research Publishing Inc.

This work is licensed under the Creative Commons Attribution International License (CC BY). http://creativecommons.org/licenses/by/4.0/

c) (i) Open Access

\begin{abstract}
Objectives: Bhutan was the first country to invest in "gross national happiness". Health care professionals usually report higher levels of happiness. In the last decade many physicians were reportedly dissatisfied with their lives and careers: "unhappy physicians". We aimed to assess levels of happiness amongst Bhutanese physicians. Methods: Bhutanese physicians endorsed the Satisfaction with Life Scale (SWLS) and a demographic questionnaire. Results: Of 176 physicians in Bhutan, 110 physicians completed the survey: $25.5 \%$ women and $74.5 \%$ men. Mean age was 36.9 years. Mean SWLS score for all physicians was $23.5 \pm 6.9$. Conclusions: Only two thirds (66.5\%) of the Bhutanese physicians who have participated in this study were satisfied with life, which was significantly lower than rate in the Bhutanese general population or among Israeli Physicians participating in a similar study.
\end{abstract}

\section{Keywords}

Physicians, Satisfaction, Gross National Happiness

\section{Introduction}

Satisfaction with life or happiness has variable definitions based on researchers' orientation and laypersons concepts. Currently, happiness and satisfaction with life are two of the main constructs studied in the emerging field of positive psychology. Satisfaction is the contentment that one feels when one has fulfilled a desire, need, or expectation. Satisfaction indicates being content, feeling adequate, of being acceptable, of being good enough, it is more about meeting an expectation, there is a standard and we can be closer or further from it. Happiness is

\footnotetext{
${ }^{*}$ Corresponding author.
} 
a positive feeling or a state of well-being. There are several sources contributing to humans' happiness: pleasure (usually sensory), engagement (absorption of an enjoyed yet challenging activity), relationships (social ties), meaning (a perceived quest or belonging to something bigger) or accomplishments (having realized tangible goals). Peterson and colleagues [1] measured life satisfaction and endorsed three different ways to be happy; through pleasure, engagement, and meaning. Each of these three orientations individually predicted life satisfaction. Survey participants scoring low on all three orientations reported having low life satisfaction.

Satisfaction with life has been defined as "a person's cognitive and affective evaluations of his or her life" and denotes the presence of positive emotion, the absence of negative emotion, and a cognitive judgment of satisfaction and fulfillment [2]. The Organization for Economic Co-operation and Development (OECD) Better Life Index [3] stated that life satisfaction measures how people evaluate their life as a whole rather than their current feelings. Evaluating feelings can be very subjective, but is a useful complement to more objective data when comparing quality of life across countries. Subjective data can provide a personal evaluation of an individual's health, education, income, personal fulfillment and social conditions. Happiness or subjective well-being can be measured in terms of life satisfaction, the presence of positive experiences and feelings, and the absence of negative experiences. Two emotions, hope and optimism are usually oriented towards reaching of goals, and the perception of those goals, optimism and pessimism are linked to symptoms of higher life satisfaction and depression respectively [4].

Happy people have better quality of life, and research in the behavioral, social, and medical sciences is continuing to identify other benefits of happiness, including better health [5]. However reports of physicians that are unhappy with their careers in medicine, with a significant minority of junior doctors considering leaving medicine have caused concern amongst physicians' professional organizations [6]. The most obvious cause of doctors' unhappiness is that they feel overworked and under supported. Trained in pathophysiology, diagnosis, and treatment, physicians spend more time involved with issues like management, improvement, finance, law, ethics, and communication in the developed countries, and workload and pay, though important, do not fully explain the problem. While most physicians continue to report overall career dissatisfaction, only a small fraction of physicians are dissatisfied with their life [7]. Several studies deal with the growing discontent of doctors and attempt to unravel the causes underlying this attitude [8] [9]. There are good reasons for these studies; physicians who are satisfied with their careers are likely to provide better health care than dissatisfied ones. Moreover, it has been noted [10] that dissatisfaction, if prolonged, may result in health problems for the physicians themselves. The causes for physicians' unhappiness herein mentioned might be partly offset by taking into account communication and ethical aspects in the primary education of medical students [11] [12].

The term "gross national happiness" was coined by Bhutan's fourth Dragon King, Jigme Singye Wangchuck, the father of the current king, who opened Bhutan to the age of modernization. It's based on the premise that true development occurs when material and spiritual development complements each other and highlights both the physical and mental well-being of the individual. He used this phrase to signal his commitment to build an economy that would serve Bhutan's unique culture based on Buddhist spritual values. There are four pillars of gross national happiness: promotion of sustainable development, preservation and promotion of cultural values, conservation of the natural environment, and establishment of good governance. At this level of generality, the concept of gross national happiness is transcultural-a nation need not be Buddhist to value and achieve the above pillars. The Centre for Bhutan Studies, developed a sophisticated survey instrument to measure the population's general level of well-being, and the country shifted the focus from spreading gross national happiness globally to the well-being of people within Bhutan [13].

A gross national happiness survey has been conducted several times in Bhutan, with the pilot survey in 2006 (350 respondents), and in 2007 (950 respondents). In 2010, the government carried out an extensive analysis of gross national happiness index, which is directly proportional to happiness. It was launched by the center for Bhutan studies and published in 2012. Bhutan's Gross National Happiness index is comprised of nine different domains of human-well being: 1) Psychological wellbeing, 2) Health, 3) Time use, 4) Education, 5) Cultural diversity and resilience, 6) Good governance, 7) Community vitality, 8) Ecological diversity and resilience, and 9) Living standard. Bhutan was left out of both 2012 and 2013 "world happy report" although rated as the happiest country in Asia and the eighth-happiest in the world 2006 [14].

A satisfaction with life survey of physicians was never conducted in Bhutan, though physician's voices of dissatisfaction were heard quite often. The present study aimed to provide these unique data. 


\section{Method}

During the period December 2013 to April 2014, we presented the aims of the survey to the physicians working in different areas of Bhutan, during professional meetings, and by e-mail. The only selection criteria for participation in the survey were for a physician to have formal medical training and certification. The questionnaire was made available on-site during professional meetings and delivered by e-mail to physicians indicating this mode as the preferred method. Participants were asked to complete the SWLS as well as a short questionnaire detailing personal data. One hundred and ten physicians (62.5\% of the country's physicians) have participated.

The present study utilized the Satisfaction with Life Scale (SWLS) originally developed by Diener and colleagues [15]. The SWLS was developed to assess satisfaction with people's lives as a whole. The scale does not assess satisfaction with specific life domains, such as health or finances, but allows subjects to integrate and weigh these domains in whatever way they choose. The SWLS is a short, 5-item instrument designed to measure global cognitive judgments of one's life. It takes only a few minutes to complete. The scale's items are: 1) In most ways my life is close to my ideal, 2) The conditions of my life are excellent, 3) I am satisfied with my life, 4) So far I have gotten the important things I want in life and 5) If I could live my life over, I would change almost nothing. Items are rated on a 1 - 7 scale as follows: 1 -Strongly disagree, 2-Disagree, 3-Slightly disagree, 4-Neither agree nor disagree, 5-Slightly agree, 6-Agree and 7-Strongly agree. The final score is the arithmetic total of all item scores reflecting satisfaction with life as follows: 35 - 31 Extremely satisfied, 26 - 30 Satisfied, 21 - 25 Slightly satisfied, 20 Neutral, 15 - 19 Slightly dissatisfied, 10 - 14 Dissatisfied and 5 - 9 Extremely dissatisfied [16] [17] which has been reviewed and validated later.

This study was submitted to and approved by our institutional ethics committee (Abarbanel MHC IRB). Verbal informed consent was obtained from all participants.

\section{Statistical Analysis}

Data were analyzed using a paired-samples and independent-samples approach. The two-tailed t-test and nonparametric test were undertaken to test for differences between the evaluations for quantitative parameters. Examination of differences between the categorical parameters was based on the Pearson Chi-square and Fisher's exact tests. All tests applied were two-tailed, and p value of 5\% or less was considered statistically significant.

The data was analyzed using the Statistical Analysis System software, SAS Institute $6^{\text {th }}$ version $\left(4^{\text {th }}\right.$ edition, Cary, NC, SAS Institute, 1990).

\section{Results}

\section{Health System in Bhutan}

The Ministry of Health has provided universal health care in Bhutan since the 1970s. Health care infrastructure and services are planned and developed through Five Year Plans of the Ministry of Health.

The major Bhutanese legislation establishes a framework for personnel. The Medical and Health Council Act of 2002 incorporates the Medical and Health Council as a legal entity to regulate medical schools, courses, and professional credentials. As of 2013, there were 32 hospitals across Bhutan. Every district has a number of smaller medical facilities.

These hospitals and smaller facilities are supported by nearly four thousand Ministry of Health employees. There are 176 doctors and 41 drungtshos (traditional physicians). The great majority of physicians are general practitioners with very few specialists [18].

During the study period, 110 physicians completed the survey. They represent all specialties of medicine. Mean age $( \pm S D)$ for the group was $36.9 \pm 9.01$ years, and there were 28 women and 82 men.

The mean total SWLS score for all 110 physicians was $23.5 \pm 6.9$. Categorically, this translates to $66.5 \%$ of participants being "satisfied” with their lives (the sum of "slightly satisfied”, "satisfied” and "very satisfied”). A small minority, 17.3\% were extremely satisfied, 29\% satisfied and 20\% slightly satisfied. There were very few (3.6\%) physicians who were neutral, 17.3\% slightly dissatisfied, 9\% dissatisfied, and 3.6\% extremely dissatisfied.

Pearson correlation coefficients were calculated for age and gender. There was an overall trend towards a positive correlation with increasing age, and female gender. This trend did not reach statistical significance; $\mathrm{r}=$ $0.02, \mathrm{p}=0.7$ and $\mathrm{r}=0.17, \mathrm{p}=0.8$ respectively. 
It is of interest to note that satisfaction scores were significantly lower than those reported for the general population of Bhutan, and for Israeli physicians. The general Bhutanese population reports happiness levels in excess of $80 \%$ of participants in surveys [13].

\section{Discussion}

Several gross national happiness surveys were conducted in Bhutan but satisfaction with life of physicians was never quantified, though physician's voices of dissatisfaction were heard quite often. The present study aimed to measure life satisfaction among Bhutanese physicians and the majority (66.5\%) reported that they were "satisfied" with their lives. The level of such satisfaction with life in our sample was not in accord with the findings among the general population according to the Gross National Happiness Index; where only $10.4 \%$ of the population was found to be unhappy [13]. Interestingly, while age was associated with decrease in life satisfaction in the general population, it was positively associated with physicians' happiness.

Humans frequently believe that making more money will make them happier and more satisfied. There is a myth that "money makes humans happy", but the correlation between the money and happiness is quite small. Nobel prize winner, Psychologist, Daniel Kahneman put forward the idea that the reason humans continue to think money makes them happier is that chasing it leads to conventional achievements like being able to afford a big house, a car and social status [19]. However, Bhutanese physicians are underpaid, which leads to feelings of justified dissatisfaction. Money is a basic need to allow confidence, independence and freedom of choice and should not be regarded just as a materialistic issue [20].

Money can buy you happiness, but not much, and above a modest threshold, more money does not mean more happiness. The breadth and depth of humans' social connections are the best predictors of their happiness [21]. In a study "Beyond Money, Toward an Economy of Well-Being" [22] argued that economic indicators were extremely important in the early stages of economic development, when the fulfillment of basic needs was the main issue but as societies grow wealthy, however, differences in well-being are less frequently due to income, and are more frequently due to factors such as social relationships and enjoyment at work. Our study supports the above findings, physicians who were married and settled with a family with good social support were happier than the young unmarried ones, who are new to the health system and possibly adjusting to the new social environment. In Israel, a similar study [23] was conducted and found that $84 \%$ of the physicians who participated reported being satisfied with their life.

In Buddhism, happiness cannot be achieved in isolation. The happiness of one depends upon the happiness of all and the happiness of all depends upon the happiness of one. This is because all life is interdependent. In order to be happy, one needs to cultivate wholesome attitudes towards others in society and towards all sentient beings. Ultimate happiness is only achieved by overcoming craving in all forms. By practicing four immeasurable; 1) loving-kindness, 2) compassion, 3) appreciative joy and 4) equanimity, they are directed to an immeasurable number of sentient beings, it is the best way of cultivating wholesome attitudes towards all sentient beings [24]. In Bhutan, being a Buddhist country, the expectations from the general population is that physicians' should be serving the people in need. Although one can wonder why life satisfaction among Bhutanese physicians is significantly lower than that of the general population in Bhutan and in comparison to Israeli physicians the explanation may lie in a complex interaction of overwork, underpayment and social pressure.

A study to explore factors associated with physician career satisfaction, work-life balance, and burnout by [25], indicated that physicians could struggle with work-life balance yet remain highly satisfied with their career. Burnout was found to be an important predictor of career satisfaction, and control over schedule and work hours were the most important predictors of work-life balance and burnout. Physicians' gender, age, and specialty were not strong independent predictors of career satisfaction, work-life balance, or burnout. In addition, rural primary care physicians are reportedly less satisfied with work and life compared to their urban [26]. Accordingly, many of the young Bhutanese physicians who are placed at the remote areas were more unsatisfied, and unhappier, claiming the hardships they had to face, in terms of physical as well as mental challenges. The most obvious cause of doctors' unhappiness is that they feel overworked and under supported. Trained in pathophysiology, diagnosis, and treatment, physicians spend more time involved with issues like management, improvement, finance, law, ethics, and communication in the developed countries, and workload and pay, though important, do not fully explain the problem [27].

Limitations of the present study include: 1) the data are self-reported; 2) the data are cross-sectional so that causal relations are subject to interpretation; 3) the sampling undertaken in professional academic meetings fa- 
vors physicians who are possibly more socially and academically conscious and finally 4) no specific career related questions were posed. The SWLS reflects happiness indirectly. The association between career satisfaction and satisfaction with life may not be straight forward and we caution overlapping these two concepts. However, this is true for all survey data sets. Strengths of this study include: a) easy to use measurement to assess global satisfaction; b) high completion rate of questionnaires and c) ability to compare data to a national and international study of satisfaction and happiness.

\section{Conclusion}

Satisfaction with life amongst Bhutanese physicians cannot be correlated with that of the general population and it was significantly lower than that of physicians in Israel. However, our findings suggest that happiness of physicians in Bhutan may be sustained by factors related to the personal, family, religious and social domains unrelated to the professional sphere. The present small study sheds light on an important issue for all practicing physicians. It should be considered as a preliminary research and further replication.

\section{Acknowledgements}

We thank Dr. Amira Orr, MD, who contributed towards the article and was involved in revising it critically for important intellectual content.

\section{Competing Interests}

The authors declare that they have no competing interests.

\section{Authors Contribution}

UD carried out the survey, participated in the analysis and drafted the manuscript. MS and IM participated in the design of the study and performed the literature search and analysis. YB conceived of the study, and participated in its design and coordination and helped to draft the manuscript.

All authors read and approved the final manuscript.

\section{References}

[1] Peterson, C., Park, N. and Seligman, M.E.P. (2005) Orientation to Happiness and Life Satisfaction; The Full Life verses the Empty Life. Journal of Happiness Studies, 6, 25-41. http://dx.doi.org/10.1007/s10902-004-1278-z

[2] Diener, E. and Seligman, M.E. (2002) Very Happy People. Psychological Science, 13, 81-84. http://dx.doi.org/10.1111/1467-9280.00415

[3] OECD Better Life (2013) Index Life Satisfaction.

[4] Chang, E.C. and Sanna, L.J. (2001) Optimism, Pessimism, and Positive and Negative Affectivity in Middle-Aged Adults: A Test of a Cognitive-Affective Model of Psychological Adjustment. Psychology and Aging, 16, 524-531. http://dx.doi.org/10.1037/0882-7974.16.3.524

[5] Lyubomirsky, S., King, L. and Diener, E. (2012) The Benefits of Frequent Positive Affect: Does Happiness Lead to Success? Psychological Bulletin, 131, 803-855. http://dx.doi.org/10.1037/0033-2909.131.6.803

[6] Smith, R. (2001) Why Are Doctors So Unhappy? British Medical Journal, 322, 1073-1074. http://dx.doi.org/10.1136/bmj.322.7294.1073

[7] Mechanic, D. (2003) Physician Discontent. Challenges and Opportunities. Journal of the American Medical Association, 290, 941-946. http://dx.doi.org/10.1001/jama.290.7.941

[8] Kassirer, J. (1998) Doctor Discontent. New England Journal of Medicine, 339, 1543-1545. http://dx.doi.org/10.1056/NEJM199811193392109

[9] Edwards, N., Kornacki, M.J. and Silversin, J. (2002) Unhappy Doctors: What Are the Causes and What Can Be Done? British Medical Journal, 324, 835-838. http://dx.doi.org/10.1136/bmj.324.7341.835

[10] Sundquist, J. and Johannsson, S.E. (2000) High Demand, Low Control, and Impaired General Health: Working Conditions in a Sample of Swedish General Practitioners. Scand Journal of Public Health, 28, 123-131. http://dx.doi.org/10.1177/140349480002800208

[11] Carufel-Wert, D.A., Younkin, S., Foertsch, J., et al. (2007) LOCUS: Immunizing Medical Students against the Loss of 
Professional Values. Family Medicine, 39, 320-325.

[12] Kumagai, A.K. (2008) A Conceptual Framework for the Use of Illness Narratives in Medical Education. Academic Medicine, 83, 653-658. http://dx.doi.org/10.1097/ACM.0b013e3181782e17

[13] The Centre for Bhutan Studies (2011) Gross National Happiness.

[14] White, A. (2006) The First Ever World Map of Happiness. NEWS, University of Leicester, Leicester.

[15] Diener, E., Emmons, R.A., Larson, R.J. and Griffin, S. (1985) The Satisfaction with Life Scale. Journal of Personality Assess, 49, 71-75. http://dx.doi.org/10.1207/s15327752jpa4901 13

[16] Pavot, W.G., Diener, E., Colvin, C.R. and Sandvik, E. (1991) Further Validation of the Satisfaction with Life Scale: Evidence for the Cross-Method Convergence of Well-Being Measures. Journal of Personality Assess, 57, $149-161$. http://dx.doi.org/10.1207/s15327752jpa5701_17

[17] Pavot, W. and Diener, E. (1993) Review of the Satisfaction with Life Scale. Psychological Assess, 5, 164-172. http://dx.doi.org/10.1037/1040-3590.5.2.164

[18] Ministry of Health (Government of Bhutan) (2010) Annual Health Bulletin 2010.

[19] Kahneman, D., Krueger, A.B., Schkade, D., Schwarz, N. and Stone, A.A. (2006) Would You Be Happier If You Were Richer? A Focusing Illusion. Science, 312, 1908-1910. http://dx.doi.org/10.1126/science.1129688

[20] Howell, R.T., Chenot, D., Hill, G. and Howell, C.J. (2011) Momentary Happiness: The Role of Psychological Need Satisfaction. Journal of Happiness Studies, 12, 1-15. http://dx.doi.org/10.1007/s10902-009-9166-1

[21] Helliwell, J.F. and Putnam, R.D. (2004) The Social Context of Well-Being. Philosophical Transactions of the Royal Society B, 359, 1435-1446. http://dx.doi.org/10.1098/rstb.2004.1522

[22] Diener, E. and Seligman, M.E. (2004) Beyond Money: Toward an Economy of Well-Being. Psychological Science in the Public Interest, 5, 1-31. http://dx.doi.org/10.1111/j.0963-7214.2004.00501001.x

[23] Barak, Y., Tishler, M. and Aizenberg, D. (2011) Satisfaction with Life amongst Psychiatrists and General Physicians: Demographic and Career Variables. Open Journal of Psychiatry, 1, 122-125. http://dx.doi.org/10.4236/ojpsych.2011.13018

[24] Buddhist Studies for Primary and Secondary Students, Unit Six: The Four Immeasurables. Buddhanet.net.

[25] Thommasen, H., Weyde, M.P.V., Alex, C., Michalos, A.C., Zumbo, B. and Hagn, C.A. (2002) Satisfaction with Work and Quality of Life among British Columbia’s Physicians: A Review of the Literature; Are Rural Primary Care Physicians Less Satisfied with Work and Life Compared to Their Urban Counterparts? British Columbia Medical Journal, 44, 188-195.

[26] Keeton, K., Fenner, D.E., Johnson, T.R. and Hayward, R.A. (2007) Predictors of Physician Career Satisfaction, WorkLife Balance, and Burnout. Obstetrics and Gynecology, 109, 949-955. http://dx.doi.org/10.1097/01.AOG.0000258299.45979.37

[27] Smith, R. (2001) Why Are Doctors So Unhappy? British Medical Journal, 322, 1073-1074. http://dx.doi.org/10.1136/bmj.322.7294.1073 